\title{
Factors Affecting Uric Acid Changes in Pulmonary Tuberculosis Patients Who Received Oral Anti Tuberculosis Therapy During One Month
}

\author{
Dedy Sasongko ${ }^{1}$, Helmia Hasan ${ }^{1}$ \\ ${ }^{I}$ Department of Pulmonology and Respiratory Medicine, Faculty of Medicine, Universitas Airlangga, \\ Dr. Soetomo Teaching Hospital, Surabaya-60131, Indonesia
}

\begin{abstract}
Background: Pyazinamide (PZA) and Ethambutol (ETB) are tuberculosis drugs that can increase uric acid levels by decreasing excretion and increasing uric acid reabsorption. Increased levels of uric acid can cause arthritis, arthralgia and gout.

Objective: To evaluate the association of uric acid levels with age, sex and body mass index (BMI) and arthralgia incidence.

Method: The study was conducted in the lung outpatient treatment room at the Department of Pulmonology and Respiratory Medicine. Method were uric acid levels examination before OAT administration, at week 2 and 4. Paired t tests and spearman correlation test were used to analyze the association between sex, age, BMI and arthralgia with increased uric acid levels. The incidence of hyperuricemia and arthralgia were performed in percentage.

Result: Seventeen subjects consisting of 9 (52.9\%) males and 8 (47.1\%) females who received oral antituberculosis category 1 mostly had normal BMI prior to treatment ( 9 patients, $52.9 \%$ ). Uric acid levels increased significantly $(\mathrm{p}<0.005)$ at week 2 and 4 than before Oral Anti Tuberculosis (OAT) treatment. It was found significant relationship $(\mathrm{p}<0.005)$ between increased uric acid levels and arthralgia with hyperuricemia incidence of $82.35 \%$ and arthralgia incidence of $35.29 \%$. There was no significant association $(\mathrm{p}<0.005)$ between increased uric acid levels with sex, age and BMI.
\end{abstract}

Conclusion: It was found a high incidence of hyperuricemia $(82.3 \%)$ in ETB and PZA treatment while symptomatic $35.29 \%$.

Keywords: Tuberculosis, ethambutol, pyrazinamide, uric acid, hyperuricemia, sex, age, body mass index, arthralgia.

\section{Introduction}

Tuberculosis (TB) is still a serious health problem in both developing and developed countries and the

\section{Correspondence Author:}

\section{Helmia Hasan}

Department of Pulmonology and Respiratory

Medicine, Faculty of Medicine, Universitas Airlangga,

Dr. Soetomo, Teaching Hospital, Surabaya-60131,

Indonesia

e-mail: hasanhelmia@gmail.com incidence is rising countinously ${ }^{1-3}$. In 1993, the World Health Organization (WHO) declared TB as "Global Emergency" and at that time it was estimated that there were about 7-8 million cases where 1.3-1.6 million deaths annually. In 2010, the incidence of TB increased by approximately 8.5-9.2 million cases, 128 cases per 100,000 populations spread across Asia (59\%), Africa (26\%), Middle East (7\%), Europe (5\%), and America (3\%). Based on WHO's Global TB Control 2011, Indonesia was among the 22 high burden countries (HBC), the fourth largest contributor to TB cases with 0.37-0.54 million cases. The discovery of new cases of 
acid-resistant TB (ARB) positive was 19,797 cases in 2011. According to the Ministry of Health at the end of 2010, Indonesia had achieved $77.3 \%$ new case finding of $70 \%$ targeted and $89.7 \%$ treatment success from $85 \%$ targeted while the death rate was reduced by more than $50 \%$ from 92 cases per 100,000 in 1990 to 27 cases per $100,000 .^{4,5}$

TB treatment administration in the Direct Observe Treatment Short-course (DOTS) often causes side effects from treatment. Some of the drugs used in tuberculosis therapy often interfere liver and kidney function. It was reported an increased levels of uric acid due to Oral Anti Tuberculosis (OAT) treatment in patients, especially triggered by the administration of pyrazinamide (PZA) and ethambutol (ETB). A study of 226 patients between January to December 2006 who underwent OAT therapy at NHO Hospital, Nagoya reported that $84.5 \%$ of patients had hyperuricemia (uric acid $>8 \mathrm{mg} / \mathrm{dL}$ ) and $4.42 \%$ had arthralgia. Other research reported that $48.4 \%$ had hyperuricemia and $15.8 \%$ arthralgia on PZA administration over 1 month. In Khasmir, India, 50\% of patients given OAT therapy had elevated levels of uric acid (hyperuricemia) at week 6 and 8. Studies in Pakistan reported that $63.8 \%$ hyperuricemia and $22 \%$ arthralgia at week 2 and $8^{6-8}$.

The incidence of hyperuricemia in the community varies widely, it is between $2.3-17.6 \%$ based on western literature. In the United States, men aged 18 years had prevalence of $1.5 \%$. In New Zealand, there were 1-18 people per a million population suffering from hyperuricemia. The magnitude of hyperuricemia incidence in Indonesia is not known clearly. Research conducted in Denpasar, Bali obtained the prevalence of $18.2 \%$. While other studies estimated that there was $5-30 \%$ hyperuricemia in the general population and the prevalence might be higher in certain ethnic groups. The high prevalence of hyperuricemia, in some Asian countries and could also occur in Indonesia, especially in Surabaya, some may be caused by the use of PZA and ETB. Monitoring of side effects due to the use of OAT should receive special attention, especially on health services that provide treatment for tuberculosis patients therefore that side effects can be prevented. Hyperuricemia actually affects not only an increase of arthralgia and gout arthritis, but several studies or journals suggest that hyperuricemia may increase risk of hypertensive to cardiovascular, cardiovascular, cerebral vascular accident (CVA), urolithiasis to nephropathy gout and metabolic syndrome ${ }^{9-11}$.
Previous studies had reported high rates of hyperuricemia due to the use of OAT in some sites, but the studies did not elucidate some factors beyond the OAT administration of patients who may be able to induce hyperuricemia. Hyperuricemia caused by drugs such as ETB and PZA, is theoretically related to several factors such as body mass index (BMI), sex and age. Looking at the existing phenomenon researchers are interested to observe and analyze several other factors related to hyperuricemia in the administration of OAT.

\section{Method}

The subjects were tuberculosis patients who met inclusion and exclusion criteria. The inclusion criteria were tuberculosis patients receiving OAT treatment containing PZA and ETB, aged 15-65 years. The exclusion criteria were gout arthritis, diabetes mellitus, renal impairment, heart disease, malignancy, hepatobiliary disease, high purine diet (at screening under hyperuricemic conditions), alcohol drinking habits, drugs use such as diuretics, allopurinol, people with gout/hiperurisemia, psoriasis, myeloproliferative and lymphoperative diseases. Subjects who met the inclusion and exclusion criteria but in the execution of the study allergic to OAT containing PZA and ETB, stopped taking OAT containing PZA and ETB, experienced DIH (drug induced hepatitis) and died removed from the subject of research.

This was an analitical observational time series studies. The study was conducted for 2 (two) months in TB/DOTS outpatient unit Dr. Soetomo General Hospital Surabaya, Indonesia. Prior to the research, it was conducted a test of ethics with the hospital's ethical committee. The subjects identified their gender, age, education, and income. The BMI measurement was done by measuring weight and height. While measurements of uric acid levels were done by venous blood sampling as much as $2.5 \mathrm{ml}$. Then, the blood was frozen in the refrigerated before centrifuge process with $3,000 \mathrm{rpm}$ in 10 minutes. The uric acid serum was examined by enzymatic uricase-peroxidase method.

The data obtained are recorded and collected by statistical data analysis using computer statistic program SPSS for Windows version 17.0 (SPSS, Inc., Chicago, IL). Data of uric acid level, sex, age and BMI were analyzed by spearman correlation test $(p<0.05)$. 


\section{Result}

Respondent's Characteristic: This study aimed to determine uric acid level changes in tuberculosis patients who underwent intensive phase OAT treatment performed for 4 weeks. Most subjects were males (9 patients, $52.9 \%$ ), aged $21-30$ years old (41.2\%), junior high educated (41.2\%), had 1-3 million income/month (12 patients, $70.6 \%$ ), normal BMI (9 patients, 52.9\%, table 3).

Examination was performed on 17 subjects to determine changes in serum uric acid levels in early OAT treatment, week 2 and week 4 . The result showed $14(82.35 \%)$ subjects with hyperuricemia, 3 (17.65\%) subjects with non hyperuricemia, 8 subjects $(47.10 \%)$ with asymptomatic hyperuricemia, 6 subjects (35.29\%) with symptomatic hyperuricemia, and 6 subjects (35.29\%) with arthralgia (table 1).
Table 1. Uric Acid Level and Arthalgia Measurement

\begin{tabular}{|l|c|c|}
\hline Subject & Frequency & $\begin{array}{c}\text { Percentage } \\
\text { (\%) }\end{array}$ \\
\hline Hyperuricemia & 14 & 82.35 \\
Male & 7 & 41.18 \\
Female & 7 & 41.18 \\
Non Hyperuricemia & 3 & 17.65 \\
Male & 2 & 11.76 \\
Female & 1 & 5.89 \\
Asymptomatic Hyperuricemia & 8 & 47.01 \\
Male & 5 & 29.41 \\
Female & 3 & 17.65 \\
Symptomatic Hyperuricemia & 6 & 35.29 \\
Male & 2 & 11.76 \\
Female & 4 & 23.53 \\
Arthalgia & 6 & 35.29 \\
Male & 2 & 11.76 \\
Female & 4 & 23.53 \\
\hline
\end{tabular}

The average of uric acid in pre OAT was $3.74 \pm$ 1.25 , week 2 was $9.35 \pm 4.30$, and week 4 was $9.02 \pm$ 5.66 (table 2).

Table 2. Uric Acid Level Measurement

\begin{tabular}{|l|c|c|c|c|}
\hline Urid Acid Levels & Minimum & Maximum & Average & SD \\
\hline Pre OAT & 2.00 & 5.80 & 3.74 & 1.25 \\
Week -2 & 3.10 & 20.10 & 9.35 & 4.30 \\
Week -4 & 1.10 & 24.50 & 9.02 & 5.66 \\
\hline
\end{tabular}

The results of uric acid level of pre-OAT, after week 2 and after week 4 based on the characteristics of the subject could be seen in table 3 and figure 1 .

Table 3. Uric Acid Level Measurement and Subject Characteristic

\begin{tabular}{|c|c|c|c|c|}
\hline \multirow{2}{*}{ Subject } & \multirow{2}{*}{$\mathbf{N}$} & \multicolumn{3}{|c|}{ Average \pm SD (mg/dl) } \\
\hline & & Pre OAT & Week -2 & Week -4 \\
\hline \multicolumn{5}{|l|}{ Sex } \\
\hline Male & 9 & $3.79 \pm 1.08$ & $9.11 \pm 5.25$ & $8.57 \pm 6.93$ \\
\hline Female & 8 & $3.70 \pm 1.51$ & $9.52 \pm 3.28$ & $9.54 \pm 4.23$ \\
\hline \multicolumn{5}{|l|}{ Age } \\
\hline $21-30$ years & 7 & $3.79 \pm 1.37$ & $8.41 \pm 5.44$ & $9.09 \pm 7.34$ \\
\hline $31-40$ years & 2 & $3.25 \pm 0.63$ & $11.35 \pm 0.21$ & $7.25 \pm 7.99$ \\
\hline $41-50$ years & 4 & $3.85 \pm 1.48$ & $10.30 \pm 3.79$ & $8.75 \pm 3.91$ \\
\hline $51-60$ years & 4 & $3.85 \pm 1.46$ & $9.08 \pm 4.38$ & $10.08 \pm 4.86$ \\
\hline \multicolumn{5}{|l|}{ Educational Background } \\
\hline Elementary & 5 & $3.48 \pm 1.47$ & $9.92 \pm 3.31$ & $10.26 \pm 4.90$ \\
\hline Junior High School & 7 & $4.23 \pm 1.10$ & $5.90 \pm 2.43$ & $7.57 \pm 5.85$ \\
\hline Senior High School & 3 & $3.41 \pm 1.27$ & $8.23 \pm 3.07$ & $6.93 \pm 3.12$ \\
\hline College & 2 & $4.85 \pm 0.21$ & $17.00 \pm 4.24$ & $15.45 \pm 12.78$ \\
\hline
\end{tabular}




\begin{tabular}{|l|c|c|c|c|}
\hline \multirow{2}{*}{ Subject } & \multirow{2}{*}{ N } & \multicolumn{3}{|c|}{ Average \pm SD (mg/dI) } \\
\cline { 3 - 5 } & & Pre OAT & Week -2 & Week -4 \\
\hline Income/Month & & & & $10.58 \pm 2.52$ \\
$<1$ million & 12 & $3.75 \pm 1.07$ & $8.15 \pm 2.05$ & $8.73 \pm 6.59$ \\
$1-3$ million & 1 & $3.81 \pm 1.39$ & $10.17 \pm 4.73$ & $6.40 \pm 0.00$ \\
$>3$ million & & $3.00 \pm 0.00$ & $4.50 \pm 0.00$ & \\
\hline BMI & 3 & & & $6.37 \pm 1.45$ \\
Very thin & 4 & $2.30 \pm 0.50$ & $5.70 \pm 1.38$ & $9.65 \pm 10.35$ \\
Thin & 9 & $4.13 \pm 1.30$ & $9.50 \pm 7.38$ & $9.24 \pm 4.38$ \\
Normal & $4.08 \pm 1.27$ & $10.72 \pm 2.83$ & $12.50 \pm 0.00$ \\
Overwight & 1 & $3.00 \pm 0.00$ & $7.50 \pm 0.00$ & \\
\hline
\end{tabular}

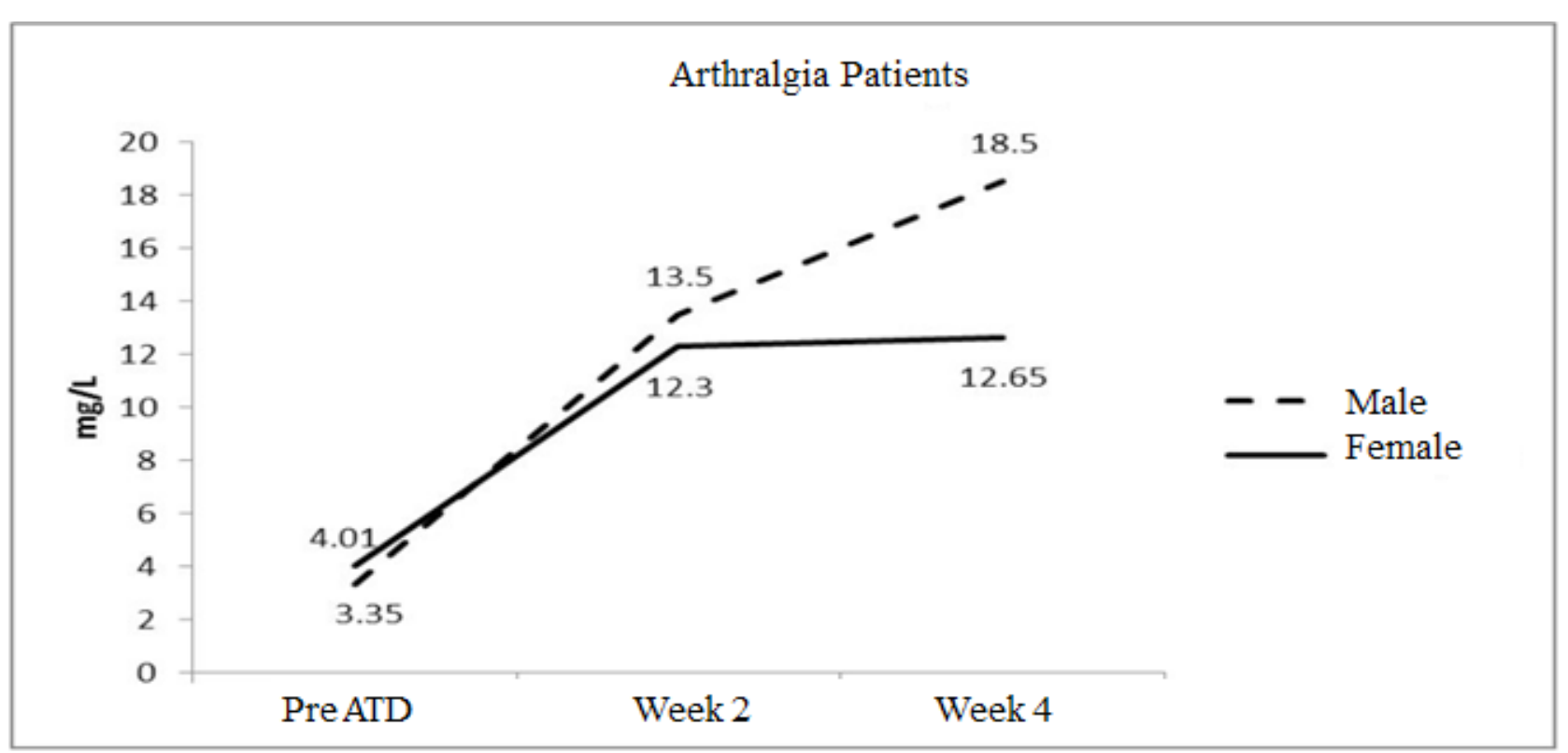

Figure 1. Average of Uric Acid on Arthralgia Patients

Relationship between Characteristics and Uric Acid Level: The statistical test with Spearman correlation obtained $\mathrm{p}>0.05$ on every characteristic except uric acid level relationship with arthralgia on week 2 of OAT $(\mathrm{r}=$ $0.603 ; \mathrm{p}=0.010)$ and week $4(\mathrm{r}=0.805 ; \mathrm{p}=0.000 ;$ table 4$)$.

Table 4. Association between Characteristic and Uric Acid

\begin{tabular}{|c|c|c|c|}
\hline \multicolumn{2}{|c|}{ Correlation } & \multirow{2}{*}{$\mathbf{r}$} & \multirow{2}{*}{$\mathbf{p}$} \\
\hline & Uric Acid Measurement & & \\
\hline \multirow{3}{*}{ Sex } & Pre OAT & 0.060 & 0.818 \\
\hline & Week-2 & -0.072 & 0.783 \\
\hline & Week-4 & -0.205 & 0.431 \\
\hline \multirow{3}{*}{ Age } & Pre OAT & 0.256 & 0.321 \\
\hline & Week-2 & 0.135 & 0.606 \\
\hline & Week-4 & 0.155 & 0.553 \\
\hline \multirow{3}{*}{ BMI } & Pre OAT & 0.326 & 0.201 \\
\hline & Week-2 & 0.458 & 0.064 \\
\hline & Week-4 & 0.396 & 0.116 \\
\hline \multirow{3}{*}{ Arthalgia } & Pre OAT & 0.214 & 0.409 \\
\hline & Week-2 & 0.603 & 0.010 \\
\hline & Week-4 & 0.805 & 0.000 \\
\hline
\end{tabular}


There was increased uric acid levels before OAT and after 2 weeks of OAT with $p=0.000$. There was also an increase in uric acid levels before OAT and after OAT for 4 weeks with $p=0.002$ (table 5).

Table 5. Statistical paired $t$ test

\begin{tabular}{|l|c|c|}
\hline Evaluation & Average & p \\
\hline Pre OAT & 3.747 & 0.000 \\
Week-2 & 9.359 & \\
\hline
\end{tabular}

\section{Discussion}

Increased uric acid levels in patients given OAT in pre, 2 weeks and 4 weeks post OAT, were not related to sex. Previous research on hyperuricemia was associated with sex but the study was in the absence of OAT administration that could interfere uric acid excretion. Studies of some literature explained that epidemiological hyperuricemia was more common in men than women because of the influence of urinary hormone estrogen that helped uric acid expenditure in the renal proximal tubule. The estrogen hormone contributes to uric acid regulation and at menopause the estrogen hormone decreases as the incidence of increased hyperuricemia in menopausal women, this study actually showed that consistent improvement was present in uric acid levels among middle-aged female patients than in male patients and in our study subjects mostly in the non-menopausal age range ${ }^{11,12}$.

Epidemiologic surveys conducted in Bandungan, Central Java on WHO COPCORD collaboration of 4,683 samples aged 15-45 years found hyperuricemia prevalence of $24.3 \%$ in males and $11.7 \%$ in females, this indicated that a male ratio was twice higher than in women to experience hyperuricemia but in this study subjects did not receive an OAT containing ETB and PZA that could interfere uric acid excretion ${ }^{13}$.

Hyperuricemia generally occurs in adult or elderly populations, rarely in children and young women. If stratified by age, prevalence increases in the age $>65$ years in both sexes. In age $<65$ years, the prevalence of hyperuricemia in males was 4 times higher than in women. At the age of $>65$ years the ratio of hyperuricemia due to gender differences narrows to 1:3 (female: male). Although the incidence of hyperuricemia can occur at all age levels but this incidence is increased in men aged $\geq 30$ years and women after menopause or aged $\geq 50$ years, because at this age women experience disruption of estrogen hormone production ${ }^{14}$.
Research conducted on 224 samples in Sweden found a significant relationship between uric acid levels and age. There was a positive correlation between elevated uric acid levels and increased age, but the study did not provide OAT. In this age-based study, young patients (21-30 years) and old patients (51-60 years) showed consistent improvement, at week 2 and week 4 compared to age category of 31 to 40 years and 41 to 50 years that experienced a decrease in uric acid levels at week 4 . The results of this study showed that elevated levels of uric acid were not affected by age factors thus an age influence was negligible and elevated serum uric acid levels were more dominant due to OAT administration ${ }^{15}$.

A study stated that patients with BMI $\geq 25 \mathrm{~kg} /$ $\mathrm{m}^{2}$ had a 3.1-fold risk of hyperuricemia compared to patients with $\mathrm{BMI} \leq 25 \mathrm{~kg} / \mathrm{m}^{2}$ but there was no use of OAT containing ETB and PZA. In thihs study, only 1 subject had BMI $>25 \mathrm{~kg} / \mathrm{m}^{2}$ or overweight who had hyperuricemia and no obese subjects. Another study in Japan conducted to 17500 young adult males showed a significant association between obesity with hyperuricemia and a significant association betweem increased BMI and increased uric acid level but the study did not have the factor of giving OAT. In this study there was no statistically significant relationship between BMI and increased uric acid levels ${ }^{16}$.

Tuberculosis is an infectious disease associated with nutritional and metabolic disorders in the patient's body. Response to infection is associated with increased energy expenditures and tissue damage levels. Energy expenditures needed to fight the infection of $\mathrm{M}$. tuberculosis. Characteristics of patients characterized by loss of appetite and weight loss. Complex changes occur in macronutrient metabolism such as proteins, carbohydrates and fats. Increased protein breakdown leads to reduced muscle mass in patients with tuberculosis. Tuberculosis sufferers also experience loss of protein (nitrogen), which is the result of impaired absorption of diarrhea, fluid loss, electrolytes and other nutritional reserves. In this study there were 6 subjects who had malnutrition with BMI $<18.5 \mathrm{~kg} / \mathrm{m}^{2} 17$.

Most of gout and hyperuricemia cases were asymptomatic hyperuricemia, having a primary cause background, requiring long-term control of uric acid levels. In this study, gout cases were excluded and no gout cases were observed because it was required hyperuricemia exposure for several years to cause 
gout, while hyperuricemia due to an OAT effect was more transient and at the time of exposure stopped the hyperuricemia was gradually normal. A previous study reported the incidence of $4.9 \%$ gout in blood uric acid levels $>9 \mathrm{mg} / \mathrm{dl} ; 0.5 \%$ at levels of $7-8.9 \%$ and $0.1 \%$ at levels $<7 \mathrm{mg} / \mathrm{dl}$. The incidence of cumulative gout reaches $22 \%$ after 5 years, at uric acid levels $>9$ $\mathrm{mg} / \mathrm{dl}^{18,19}$.

\section{Conclusion}

There is a significant increase in serum uric acid levels in patients with pulmonary TB who receive OAT containing PZA and ETB and a significant relationship between arthralgia with an increase in serum uric acid levels in pulmonary TB patients who get OAT. While the variables of age, sex, age and BMI exhibit the same results that there is no significant relationship with the increase in serum uric acid levels in patients with pulmonary $\mathrm{TB}$ who receive OAT.

Ethical Clearance: This study protocol was approved by ethical clearance Dr. Soetomo Surabaya, Indonesia teaching hospital research.

Conflict of Interest: The author reports no conflict of interest of this work.

Source of Funding: This study is done with individual funding.

\section{References}

1. Hikmawati D, Maulida HN, Putra AP, Budiatin AS, Syahrom A. Synthesis and Characterization of Nanohydroxyapatite-Gelatin Composite with Streptomycin as Antituberculosis Injectable Bone Substitute. Int J Biomater. 2019;2019.

2. Hasanah U, Makhfudli M, Ni'mah L, Efendi F, Aurizki GE. Peer Group Support on the Treatment Adherence of Pulmonary Tuberculosis Patients. In: IOP Conference Series: Earth and Environmental Science. IOP Publishing; 2019. p. 12033.

3. Sari NIP, Mertaniasih NM, Maruyama F. Application of serial tests for Mycobacterium tuberculosis detection to active lung tuberculosis cases in Indonesia. BMC Res Notes. 2019;12(1):313.

4. Departemen Kesehatan RI. Pedoman Nasional Pelayanan Kesehatan: Tata Laksana Tuberkulosis. 2013.
5. World Health Organization. Global tuberculosis control: WHO. 2011.

6. Sharma TN, Jain NK, Mathur BB, Nanawati V, Sharma GS, Sharma VK. Hyperuricemia and arthralgia during pyrazinamide therapy. Indian $\mathrm{J}$ Tuberc. 1981;28(2):92-7.

7. Ghulam AS, Bader RZ, Silkander S, Wasir MS. Pyrazinamide induced hyperuricemia in patients taking anti-tuberculosis therapy. JCPSP. 2004;14(3):136-8.

8. TAKI H, OGAWA K, MURAKAMI T, NIKAI T. Epidemiological survey of hyperuricemia as an adverse reaction to antituberculous therapy with pyrazinamide. Kekkaku (Tuberculosis). 2008;83(7):497-501.

9. Gowrinath K. Outcome of Directly Observed Treatment Short course (DOTS) in a case of pulmonary tuberculosis with Hyperuricemia. Indian J Tuberc. 2009;56(2):108.

10. Gustafsson D, Unwin R. The pathophysiology of hyperuricaemia and its possible relationship to cardiovascular disease, morbidity and mortality. BMC Nephrol. 2013;14(1):164.

11. Wisesa IBN, Suastika K. Hubungan Antara Konsentrasi Asam Urat Serum Dengan Resistensi Insulin Pada Penduduk Suku Bali Asli Di Dusun Tenganan Pegringsingan Karangasem. J Penyakit Dalam. 2009;10(2):110-2.

12. Şişmanlar $T$, Aslan AT, Budakoğlu I. Is hyperuricemia overlooked when treating pediatric tuberculosis patients with pyrazinamide? J Trop Pediatr. 2015;61(5):351-6.

13. Purwaningsih T. Faktor-Faktor Resiko Hiperurisemia. Universitas Diponegoro; 2009.

14. Finch W. Acute crystal-induced arthritis: Gout and a whole lot more. Postgrad Med. 1989;85(8): 273-7.

15. Lindeberg $\mathrm{S}$, Cordain L, Råstam L, Ahrén B. Serum uric acid in traditional Pacific Islanders and in Swedes. J Intern Med. 2004;255(3):373-8.

16. Poletto J, Harima HA, Ferreira SRG, Gimeno SGA. Hyperuricemia and associated factors: a crosssectional study of Japanese-Brazilians. Cad Saude Publica. 2011;27:369-78. 
17. Zachariah R, Spielmann MP, Harries AD, Salaniponi FML. Moderate to severe malnutrition in patients with tuberculosis is a risk factor associated with early death. Trans R Soc Trop Med Hyg. 2002;96(3):291-4.
18. Scott JT. Drug-induced gout. Baillieres Clin Rheumatol. 1991; 5(1):39-60.

19. Luk AJ, Simkin PA. Epidemiology of hyperuricemia and gout. Am J Manag Care. 2005;11(15 Suppl): S435-42. 